\title{
Is accelerated oxidation of lactate required for dichloroacetate to lower the level of lactate in blood?
}

\author{
Kamel S. Kamel, ${ }^{1}$ Surinder Cheema-Dhadl, and Mitchell L. Halperin \\ Renal Division, St. Michael's Hospital, 30 Bond Street, University of Toronto, Toronto, Ont., Canada M5B 1 W8
}

Received June 12, 1992

Kamel, K. S., Cheema-Dhadl, S., and Halperin, M. L. 1992. Is accelerated oxidation of lactate required for dichloroacetate to lower the level of lactate in blood? Can. J. Physiol. Pharmacol. 70: 1477-1482.

We examined mechanisms by which dichloroacetate (DCA), an activator of pyruvate dehydrogenase (PDH), led to a decrease in the concentration of lactate in blood in a unique "metabolic setting," where the concentration of lactate in blood was $5.4 \pm 0.5 \mathrm{mmol} / \mathrm{L}$. Elevated levels of lactate were induced in anaesthetized rabbits by the administration of a large dose of insulin. The rate of consumption of oxygen was $1.2 \pm 0.1 \mathrm{mmol} / \mathrm{min}$, the respiratory quotient was close to unity, and close to half of the PDH was in its active form; therefore, virtually all ATP synthesis should require flux through PDH. Hence, we predicted that DCA should not cause a significant decrease in the concentration of lactate in blood in this model. In contrast, if DCA was effective, new insights could be obtained into its mechanisms of action, at least in this setting. During steady-state hyperlactatemia, DCA was given as its sodium salt, $2 \mathrm{mmol} / \mathrm{kg}(n=10)$; a control group $(n=5)$ received equimolar $\mathrm{NaCl}$. Forty minutes later, the level of lactate in blood in the DCA group was $1.3 \pm 0.2 \mathrm{mmol} / \mathrm{L}$, significantly lower than in the $\mathrm{NaCl}$ group $(4.2 \pm 0.6 \mathrm{mmol} / \mathrm{L})$. To determine the organ(s) responsible for removing lactate, arteriovenous differences were measured in organs drained by the jugular, femoral, and hepatic veins. There was no net uptake of lactate in these drainage beds after DCA was administered. From a quantitative analysis of the rate of removal of lactate and the rate of consumption of oxygen, it seems unlikely that the majority of the decrease in lactate could be directly attributed to an increase in its oxidation.

Key words: lactic acidosis, dichloroacetate, pyruvate dehydrogenase, metabolism.

Kamel, K. S., Cheema-Dhadle, S., et Halperin, M. L. 1992. Is accelerated oxidation of lactate required for dichloroacetate to lower the level of lactate in blood? Can. J. Physiol. Pharmacol. 70 : 1477-1482.

Nous avons examiné les mécanismes par lesquels le dichloroacétate (DCA), un activateur de la pyruvate déshydrogénase (PDH), a provoqué une chute de lactate sanguin, alors que la concentration de lactate était de $5,4 \pm 0,5 \mathrm{mmol} / \mathrm{L}$. Les taux élevés de lactate ont été induits, chez des lapins anesthésiés, par l'administration d'une forte dose d'insuline. Le taux de consommation d'oxygène était de $1,2 \pm 0,1 \mathrm{mmol} / \mathrm{min}$, le quotient respiratoire se situait près de l'unité et environ la moitié de la PDH était sous sa forme active; dans un tel cas, presque toute la synthèse de l'ATP devrait impliquer la PDH. Par conséquent, nous avons émis l'hypothèse que le DCA ne devrait pas provoquer de diminution significative de la concentration de lactate sanguin chez ce modèle. Toutefois, si le DCA était efficace, de nouveaux aspects de ses mécanismes d'action seraient révélés, du moins pour cette situation métabolique. Durant une hyperlactacidémie continue, le DCA a été administré sous sa forme $\mathrm{Na}, 2 \mathrm{mmol} / \mathrm{kg}(n=10)$; un groupe témoin $(n=5)$ a reçu une dose équimolaire de $\mathrm{NaCl}$. Quarante minutes plus tard, le taux de lactate sanguin du groupe DCA a été de $1,3 \pm 0,2 \mathrm{mmol} / \mathrm{L}$, ce qui était significativement plus faible que celui du groupe $\mathrm{NaCl}(4,2 \pm 0,6 \mathrm{mmol} / \mathrm{L})$. Pour déterminer le ou les organes à l'origine de l'élimination du lactate, on a mesuré les différences artérioveineuses dans les organes drainés par les veines hépatiques, fémorales et jugulaires. Après l'administration de DCA, il n'y a pas eu de capture de lactate dans ces lits de drainage. D'après les résultats d'une analyse quantitative du taux d'élimination de lactate et du taux de consommation d'oxygène, il semble peu probable que la majeure partie de la diminution de lacate puisse être directement attribuée à une augmentation de son oxydation.

Mots clés : acidose lactique, dichloroacétate, pyruvate déshydrogénase, métabolisme.

[Traduit par la rédaction]

\section{Introduction}

It is important to define the "metabolic setting" to evaluate the impact of a therapeutic modality in the treatment of a metabolic abnormality. The example studied in this paper is the ability of dichloroacetate (DCA) to lower the concentration of lactate in blood (Stacpoole 1989). DCA has been shown to

\footnotetext{
'Author for correspondence.

${ }^{2}$ The quantity of $\mathrm{PDH}$ is potentially enormous relative to the flux it must catalyze at rest. For example, consider the quantity of pyruvate oxidized in muscle in humans during vigorous exercise. $\mathrm{O}_{2}$ consumption is $160 \mathrm{mmol} / \mathrm{min}$ and glycogen is the major fuel oxidized (Cheetham et al. 1986). This rate of $\mathrm{O}_{2}$ consumption is almost 13 -fold higher than at rest. Hence if more than $10 \%$ of $\mathrm{PDH}$ were in its active form at rest in muscle, the activity of $\mathrm{PDH}$ would not be rate limiting for the flux of pyruvate to acetyl-CoA. Moreover, a further increase in the activity of the enzyme would not necessarily mean an increase in flux because of constraints of $\mathrm{O}_{2}$ consumption and the rate of urnover of ATP, especially if carbohydrate is already the major fuel being utilized.
}

stimulate pyruvate dehydrogenase (PDH) (Stacpoole 1989; Whitehouse and Randle 1973) and, in certain circumstances, the oxidation of lactate. The metabolic setting to permit an increase in flux through PDH, however, requires an increase in demand for the products of this reaction (ultimately, an increase in turnover of ATP or the synthesis of fatty acids) or that lactate is used in preference to other fuels (e.g., fatty acids). It follows that DCA may not have the same impact or effect if it is given to a subject who is deriving this needed ATP primarily from the oxidation of carbohydrate. Moreover, it is important to perform a quantitative analysis that takes into account the rate of removal of lactate in conjunction with the rate of consumption of oxygen to evaluate whether oxidation of lactate was indeed responsible for the observations made in vivo.

The model we chose to address these issues was one where the target enzyme for DCA, PDH, was sufficiently active to permit enough flux to regenerate needed ATP. ${ }^{2}$ Therefore, we expected that DCA would not have a significant impact or, 
if effective, new insights could be gained into its mechanisms of action in vivo. Results to be reported show that DCA led to a rapid, significant reduction in the concentration of lactate in blood in our model with elevated levels of lactate in blood. This decrease in lactate did not appear to be due to an enhanced rate of oxidation of lactate because the measured arteriovenous $(\mathrm{A}-\mathrm{V})$ difference across three major venous beds, the jugular, the splanchnic area, and the femoral drainage systems, revealed net release rather than net uptake of lactate. In addition, from a quantitative analysis of the rate of removal of lactate and the rate of consumption of oxygen, it seemed unlikely that most of the lactate was removed via oxidation. To explain these data incorporating the known stimulation of PDH by DCA (Stacpoole 1989; Whitehouse and Randle 1973), we speculate that there was an enhanced removal of lactic acid via gluconeogenesis or lipogenesis in an organ(s) not drained by the jugular, splanchnic, or femoral venous beds, presumably the kidneys; in addition, there may have been a decreased rate of production of lactate to permit its level to fall so quickly.

\section{Methods}

Male New Zealand white rabbits (mean weight $4 \mathrm{~kg}$ ) were obtained from Reimans Fur Ranch, St-Agathe, Que. They were fed Purina rabbit chow until the time of the experiments. Chlorpromazine $(2.5 \mathrm{mg} / \mathrm{kg})$ was administered by the intramuscular route to sedate the animals 30 min prior to anaesthesia. Anaesthesia was induced by infusing pentobarbital sodium $(15 \mathrm{mg} / \mathrm{kg}$ body weight; Nembutal, Abbott Laboratories, Montréal, Que.) via an ear vein; small additional doses were given, as needed, to maintain a steady plane of anaesthesia. Animals were allowed to breathe spontaneously throughout the experiment. Teflon canulas were inserted in the carotid artery, the femoral vein, jugular vein, and hepatic vein for measurement of $\mathrm{A}-\mathrm{V}$ differences. The catheter in the hepatic vein was inserted via the femoral vein, and the location was verified at the end of the experiment. A balloon-tipped, flow-directed catheter was inserted into the pulmonary artery via the jugular vein for measurement of cardiac output and sampling of mixed venous blood. The temperature was monitored throughout the experiment, and animals were warmed by a heating blanket to maintain body temperature between 37 and $38^{\circ} \mathrm{C}$.

\section{Experimental protocols}

The first series of experiments was carried out to characterize the model of hyperlactatemia in which delivery of $\mathrm{O}_{2}$ was not limiting and fatty acids were not a major fuel; hence virtually all ATP needed by organs should require flux through PDH. To achieve this aim, the protocol of Haynes et al. (1988) was used. Anaesthetized rabbits $(n=5)$ received 7 units of regular insulin as an intravenous bolus plus a continuous infusion of 7 units per hour. Samples of blood were obtained at 20-min intervals from the aorta for measurement of metabolites as described below. Blood was obtained from the aorta and pulmonary artery at 80 and 120 min for measurement of hematocrit and blood gases. The cardiac ouptut was measured at 80 and $120 \mathrm{~min}$.

A second series of experiments was carried out to measure PDH activity in the three phases of this model. A sample of liver, renal cortex, and muscle was freeze clamped in liquid nitrogen in control anaesthetized rabbits $(n=4)$, in rabbits treated with insulin as above for $120 \mathrm{~min}(n=5)$, and $10 \mathrm{~min}$ after DCA $(2 \mathrm{mmol} / \mathrm{kg})$ was given as an intravenous bolus to a third group of rabbits $(n=5)$, who received insulin as described above.

The third series of experiments was performed to determine whether DCA, if administered during the steady state of hyperlactatemia, would cause a decrease in the concentration of lactate in blood and, if so, which organ(s) was (were) responsible for the removal of lactate. Rabbits were anaesthetized and received insulin as above. During the steady state with elevated levels of lactate in blood

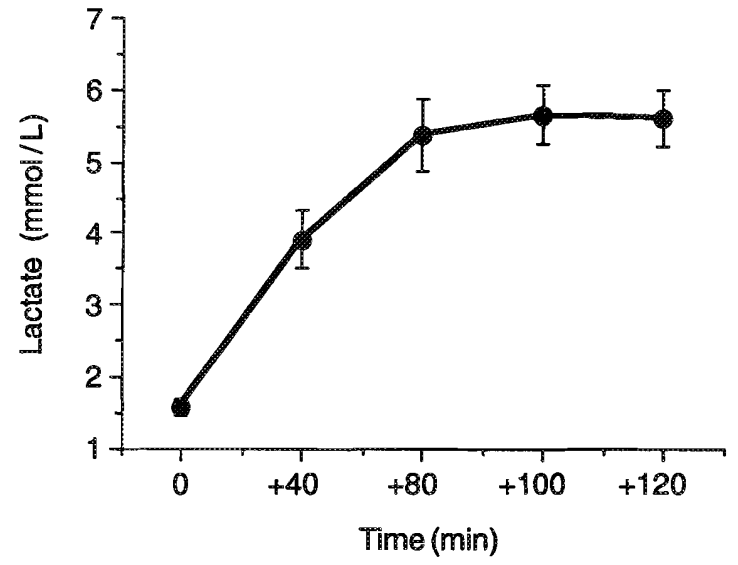

Frg. 1. Effect of insulin on the concentration of lactate in blood. For details, see text. Insulin was administered at time 0. Data are reported as means \pm SEM. A steady-state hyperlactatemia was achieved $80 \mathrm{~min}$ after the administration of insulin.

(120 min), rabbits received either the sodium salt of DCA ( $2 \mathrm{mmol} /$ $\mathrm{kg}, n=10$ ) as an intravenous bolus or equimolar $\mathrm{NaCl}$ in the control series $(n=5)$. Samples of blood for measurement of metabolites were taken from the aorta at 80 and 120 min after insulin was begun and at 10-min intervals for $40 \mathrm{~min}$ after the administration of DCA or $\mathrm{NaCl}$. Blood was obtained from the aorta and pulmonary artery at 80 and $120 \mathrm{~min}$ after insulin was begun and at $20 \mathrm{~min}$ after administration of $\mathrm{DCA}$ or $\mathrm{NaCl}$ for the measurement of hematocrit and blood gases. The cardiac output was measured at 80 and 120 min after insulin was begun and at 20 min after animals received DCA or $\mathrm{NaCl}$.

To determine the organ(s) responsible for removal of lactate, blood for measurement of metabolites was taken from the aorta, jugular vein, femoral vein, and hepatic vein at 80 and $120 \mathrm{~min}$ after insulin was begun and at 5, 10,20, and $30 \mathrm{~min}$ after the administration of DCA. It was not technically possible to obtain samples from the renal vein without excessive manipulations that led to a rise in the levels of fatty acids in the blood.

\section{Analytical methods}

The cardiac output was measured by a thermodilution method using a cardiac output computer (Swan-Ganz 93-132-SF, American Edward Laboratories, Calif.). The $\mathrm{pH}, \mathrm{PO}_{2}$, and $\mathrm{PCO}_{2}$ of the blood were measured anaerobically at $37^{\circ} \mathrm{C}$ with a digital acid-base analyzer. A portion of blood was deproteinized after collection with $1: 1 \mathrm{v} / \mathrm{v} 10 \%$ ice-cold perchloric acid for measurement of metabolites. Hematocrit, glucose, lactate, and fatty acids were measured as previously described (Halperin et al. 1985). PDH activity was measured as described by Taylor et al. (1973) for adipose tissue with the following modifications: Smaller quantities of muscle, liver, and kidney were used $(20 \mathrm{mg} / \mathrm{mL})$ and muscle samples were homogenized in the presence of $1 \%$ Triton (Sigma Chemical Company, St. Louis, Mo.) The assay was linear between 1.5 and $6 \mathrm{~min}$, and assays were conducted for $6 \mathrm{~min}$.

\section{Calculations}

The rates of consumption of oxygen and production of $\mathrm{CO}_{2}$ were calculated by multiplying the arterial minus mixed venous oxygen or $\mathrm{CO}_{2}$ content by the cardiac output. The contents of oxygen and $\mathrm{CO}_{2}$ were calculated as described by Kelman $(1966,1967)$. The respiratory quotient $(\mathrm{RQ})$ was calculated as the ratio of production of $\mathrm{CO}_{2}$ to consumption of $\mathrm{O}_{2}$.

\section{Statistical analysis}

Results are reported as means \pm SEM. Statistical analysis was formed by the Student's $t$-test. Values of $<0.05$ were considered statistically significant. Analysis was performed on a Macintosh computer using Statsview II statistical software package. 
TABLE 1. Effect of insulin and DCA on the activity of PDH

\begin{tabular}{llll}
\hline \multicolumn{1}{c}{ Treatment } & Kidney & \multicolumn{1}{c}{ Liver } & Muscle \\
\hline Control $(n=4)$ & $13 \pm 2$ & $12 \pm 1$ & $25 \pm 7$ \\
Insulin $(n=5)$ & $35 \pm 10$ & $34 \pm 13$ & $46 \pm 6^{a}$ \\
Insulin + DCA $(n=5)$ & $67 \pm 16^{a}$ & $59 \pm 15^{a}$ & $81 \pm 5^{a, b}$ \\
\hline
\end{tabular}

Note: The activity of PDH was measured as described by Taylor et al. (1973). The results are presented as means \pm SEM for the percentage of enzyme in the active form.

${ }^{a} p<0.05$ compared with the control period

$b_{p}<0.05$ compared with the insulin period.

TABLE 2. Level of metabolites in blood in the $\mathrm{NaCl}$ and DCA groups

\begin{tabular}{lcc}
\hline \hline & $\begin{array}{c}\mathrm{NaCl} \\
(n=5)\end{array}$ & $\begin{array}{c}\text { DCA } \\
(n=10)\end{array}$ \\
\hline $\begin{array}{l}\text { Glucose (mmol/L) } \\
\quad \text { Control }\end{array}$ & $6.6 \pm 0.4$ & $6.2 \pm 0.7$ \\
$\quad$ Insulin & $4.0 \pm 0.1^{a}$ & $3.6 \pm 0.2^{a}$ \\
$\quad$ Treatment & $3.5 \pm 0.2^{a}$ & $3.7 \pm 0.3^{a}$ \\
Fatty acids ( $\mu \mathrm{mol} / \mathrm{L})$ & & \\
$\quad$ Control & $1570 \pm 552$ & $871 \pm 199$ \\
$\quad$ Insulin & $641 \pm 165$ & $418 \pm 39$ \\
$\quad$ Treatment & $317 \pm 223^{a}$ & $314 \pm 15^{a}$ \\
Lactate (mmol/L) & & \\
$\quad$ Control & $1.5 \pm 0.4$ & $1.6 \pm 0.2$ \\
Insulin & $5.3 \pm 0.5^{a}$ & $5.9 \pm 0.5^{a}$ \\
$\quad$ Treatment & $4.2 \pm 0.6$ & $1.3 \pm 0.2^{b, c}$ \\
\hline
\end{tabular}

NOTE: For details, see text. The data in the insulin period are means of measurements obtained at 80 and $120 \mathrm{~min}$. The data in the treatment period are means of measurements obtained at $40 \mathrm{~min}$ after the administration of $\mathrm{NaCl}$ or DCA.

$a_{p}<0.05$ compared with the control period.

$b_{p}<0.05$ compared with the insulin period.

$c p<0.05$ compared with the $\mathrm{NaCl}$ group.

\section{Results}

\section{Model of hyperlactatemia}

In rabbits infused with insulin, there was a decline in the concentration of glucose in plasma from $6.3 \pm 0.4$ to $3.8 \pm$ $0.1 \mathrm{mmol} / \mathrm{L}$ at $80 \mathrm{~min}$ after the insulin infusion was started; similarly the level of fatty acids declined from $1103 \pm 233$ to $483 \pm 57 \mu \mathrm{mol} / \mathrm{L}$. Hence there was evidence of the metabolic actions of insulin. The concentration of lactate in blood rose from $1.5 \pm 0.2$ to $5.4 \pm 0.5 \mathrm{mmol} / \mathrm{L}$ after $80 \mathrm{~min}$ and remained in this range thereafter (Fig. 1). The rate of consumption of $\mathrm{O}_{2}$ was $1.2 \pm 0.1 \mathrm{mmol} / \mathrm{min}$ and did not vary significantly throughout the experiment. The RQ was close to unity $(1.0 \pm 0.1)$ throughout the experiment, indicating that carbohydrate rather than fatty acids was the primary fuel oxidized. Less than $25 \%$ of PDH was in its active form in liver, kidney, and muscle in control rabbits. There was almost a twofold increase in activity of the enzyme in muscle after the administration of insulin. As expected, DCA has led to a further increase in the activity of PDH (Table 1).

\section{Effect of DCA}

The concentration of lactate in blood was similar in both the DCA and $\mathrm{NaCl}$ groups $(5.9 \pm 0.5$ vs. $5.3 \pm 0.5$; Table 2 , Fig. 2). Although there was a small decrease in the concentration of lactate in blood in the saline group, this decrease was

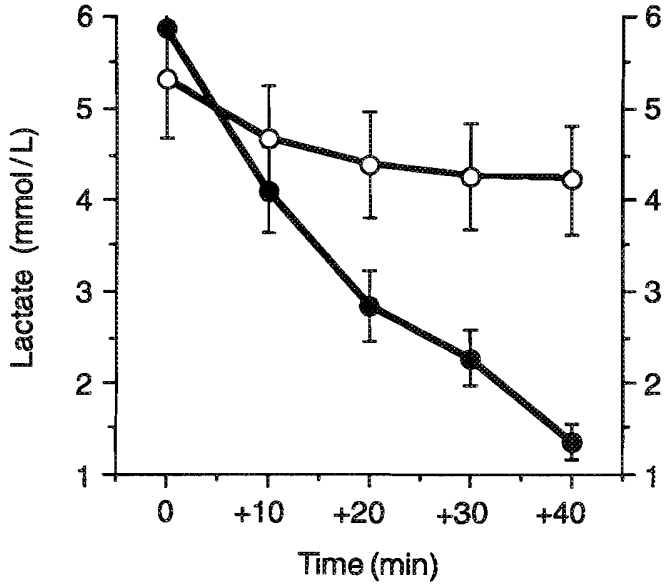

FIG. 2. Effect of DCA on the concentration of lactate. For details, see text. Data are reported as means \pm SEM for the DCA group (1) and the $\mathrm{NaCl}$ group (O). The concentration of lactate in blood was similar in both groups before the administration of DCA or $\mathrm{NaCl}$. A marked decrease in the concentration of lactate in blood was noted in the DCA group.

TABLE 3. Measured $A-V$ difference for lactate across the jugular, femoral, and splanchnic areas

\begin{tabular}{ccccc}
\hline & Time (min) & $\mathrm{A}-\mathrm{J}$ & $\mathrm{A}-\mathrm{F}$ & $\mathrm{A}-\mathrm{H}$ \\
\hline Insulin & +80 & $-0.23 \pm 0.13$ & $-0.39 \pm 0.06$ & $-0.04 \pm 0.07$ \\
& +120 & $-0.11 \pm 0.07$ & $-0.35 \pm 0.06$ & $-0.04 \pm 0.09$ \\
DCA & +5 & $-0.46 \pm 0.14^{a}$ & $-0.54 \pm 0.16$ & $-0.27 \pm 0.21$ \\
& +10 & $-0.46 \pm 0.08^{a}$ & $-0.39 \pm 0.17$ & $-0.15 \pm 0.14$ \\
& +20 & $-0.40 \pm 0.11^{a}$ & $-0.19 \pm 0.24$ & $-0.26 \pm 0.16$ \\
& +30 & $-0.22 \pm 0.12$ & $-0.03 \pm 0.22$ & $-0.10 \pm 0.08$ \\
\hline
\end{tabular}

NoTE: For details, see text. The measured $\mathrm{A}-\mathrm{V}$ difference for lactate in rabbits $(n=10)$, at 80 and 120 min after starting the infusion of insulin and at $5,10,20$, and $30 \mathrm{~min}$ after the administration of DCA (infusion began immediately after the 120 -min time of the insulin infusion). J, jugular vein; $F$, femoral vein; $H$, hepatic vein; $A$, aorta.

${ }^{u} p<0.05$ compared with insulin +120 .

much greater in the DCA group. At $40 \mathrm{~min}$, the level of lactate in blood in the DCA group was $1.3 \pm 0.2 \mathrm{mmol} / \mathrm{L}$, significantly lower than that in the saline group $(4.2 \pm 0.6 \mathrm{mmol} / \mathrm{L})$. The concentrations of glucose and fatty acids in blood were not different in the DCA group as compared with the saline group before or at 40 min after the administration of DCA or $\mathrm{NaCl}$ (Table 2). After the administration of DCA, the cardiac output was $0.6 \pm 0.1 \mathrm{~L} / \mathrm{min}$ and the rate of consumption of $\mathrm{O}_{2}$ was $1.3 \pm 0.1 \mathrm{mmol} / \mathrm{min}$, values not significantly different from those before the administration of DCA $(0.5 \pm$ $0.1 \mathrm{~L} / \mathrm{min}$ and $1.2 \pm 0.1 \mathrm{mmol} / \mathrm{min}$, respectively).

\section{A-V measurements}

To determine the organ(s) responsible for removal of lactate, the $\mathrm{A}-\mathrm{V}$ difference for lactate was measured in organs drained by the jugular, femoral, and hepatic veins. It is noteworthy that there was net production of lactate in all these beds during the steady-state interval (Table 3). This suggests that one or more organs drained by other venous systems were removing lactate to maintain the steady state. Furthermore, there was no significant uptake of lactate in any of these beds after the administration of DCA (Table 3). 


\section{Discussion}

The major finding of this study was that the level of lactate in blood decreased promptly when DCA was added, but in this model, the mechanism involved could not be explained solely by an enhanced rate of oxidation of lactate.

DCA, an activator of PDH (Stacpoole 1989; Whitehouse et al. 1974), has been shown to lower the level of lactate in blood in a variety of experimental models of lactic acidosis (Abu Romeh and Tannen 1986; Graf et al. 1985; Holloway and Alberti 1975; Johnson and Alberti 1977; Loubatières et al. 1976, 1978; Merrill et al. 1980; Park and Arieff 1982) and in some studies in humans (Blackshear et al. 1982; Stacpoole et al. 1983, 1988). The drug activates PDH and hence should stimulate the oxidation of lactate if the products of this reaction can be utilized. An increase in flux through PDH, however, requires an increase in demand for the regeneration of ATP, a need to synthesize fatty acids, or that carbohydrates replace another fuel (e.g., fatty acids) to regenerate the required amount of ATP. Therefore conclusions about the mechanism of action of DCA require that the metabolic setting under which the drug is used be clearly defined. Moreover, the stoichiometry of the rate of removal of lactate as compared with the rate of consumption of oxygen must be examined before deciding which metabolic action was responsible for the removal of lactate.

We examined the role of DCA in a specific metabolic setting characterized by a steady-state hyperlactatemia. In this model, the level of fatty acids in plasma was reduced, the RQ was close to unity, and a sufficient proportion of $\mathrm{PDH}$ was in its active form before the administration of $\mathrm{DCA}^{2}$ (Table 1). Hence flux through PDH should already be the major metabolic pathway for regeneration of ATP. In such a model, we expected that DCA would have a little quantitative impact to enhance the rate of oxidation of lactate if there was no marked increase in oxygen consumption since flux through PDH should be limited by signals related to the rate of turnover of ATP. To achieve these aims, the protocol of Haynes et al. (1988), an infusion of insulin into anaesthetized rabbits, was utilized because these authors demonstrated that glycogen in liver and muscle were the major fuels consumed in this setting; this regeneration of ATP already required flux through $\mathrm{PDH}$. We speculate that the basis for the steady-state lactatemia in this model was as follows: PDH was dephosphorylated, and hence in its active form owing to the administration of insulin (Table 1) (Cheng and Larner 1987; Denton and Halestrap 1979; Jungas 1971); control of flux through PDH was now principally due to feedback inhibition by the products of the reaction it catalyzes, acetyl-CoA and NADH together with a decrease in ADP (Neely and Morgan 1974; Newsholme and Start 1977). Although changes in concentrations of these same intermediates, and also those of citrate and AMP, should also lead to inhibition of phosphofructokinase 1 (PFK1), a greater control strength excreted at PDH than PFK1 could lead to the accumulation of lactic acid.

To our surprise, DCA led to a marked decrease in the concentration of lactate in blood (Fig. 2). The other unanticipated result was that this was achieved although there was no net uptake of lactate across three accessible major venous drainage beds; in fact, there was production of lactate, across the jugular, femoral, and splanchnic venous drainage systems (Table 3). One possible explanation for the rise in $A-V$ difference of lactate after the administration of DCA could be the transport of lactate out of the cells in exchange for DCA entry on the monocarboxylate transporter (Halestrap and Poole 1988), at least at the earlier time points. Nevertheless, there was always a net release of lactate in all these drainage beds over the 30 -min period (Table 3 ).

Although there was some decrease in the production of lactate (statistically insignificant), inhibition of glycolysis alone would not lead to removal of the existing pool of lactate, as net production of lactate still occurred in the jugular, hepatic, and femoral venous drainage systems. Therefore, although an inhibition of glycolysis in other organs might have contributed to the decrease in lactate, it does not explain the magnitude of effect of DCA to lower the level of lactate in blood. The data could be explained by an effect of DCA to enhance the removal of lactate by one or more organs other than those drained by the jugular, femoral, or splanchnic venous systems. It is noteworthy that a steady-state hyperlactatemia was maintained before the administration of DCA when there was net production of lactate across these venous beds and, therefore, one or more other organs were removing lactate to maintain the steady state.

The mechanism of removal of lacate could be via oxidation, lipogenesis, or gluconeogenesis (or conversion to alanine). It seems unlikely from a quantitative analysis of the rate of removal of lactate and the rate of consumption of oxygen that oxidation of lactate was the major mechanism for its removal (see below). The amount of lactate removed is equivalent to the reduction in its pool plus the amount of ongoing production of lactate. The concentration of lactate in blood in the DCA group fell from 5.9 to $2.3 \mathrm{mmol} / \mathrm{L}$ over $30 \mathrm{~min}$. In the saline group the concentration of lactate in blood fell from 5.3 to $4.3 \mathrm{mmol} / \mathrm{L}$ over the same period of time $(19 \%)$. Therefore it is possible that close to $20 \%$ of the drop in the concentration of lactate in the DCA group was due to dilution. The decrease in the concentration of lactate in blood that was due to the effect of DCA was then close to $2 \mathrm{mmol} / \mathrm{L}$. If the volume of distribution of lactate in these rabbits was close to $50 \%$ of their body weight, i.e., close to $2 \mathbb{L}$ (Roos 1975), then approximately $4 \mathrm{mmol}$ of lactate was removed from its pool in this time interval. Removal of $4 \mathrm{mmol}$ of lactate via oxidation would require $12 \mathrm{mmol}$ of $\mathrm{O}_{2}$ (Halperin et al. 1992); this is roughly equivalent to one-third the measured consumption of $\mathrm{O}_{2}$ by the whole animal over $30 \mathrm{~min}(1.3 \mathrm{mmol} / \mathrm{min} \times$ $30 \mathrm{~min}=39 \mathrm{mmol}$ ). Furthermore, there was no uptake of lactate across the jugular, femoral, and splanchnic venous drainage systems. If one also considers the amount of lactate that was produced and removed ${ }^{3}$ after the administration of

\footnotetext{
${ }^{3}$ The amount of ongoing production of lactate after the administration of DCA can be estimated from the measured $A-V$ difference across the jugular, femoral, and splanchnic areas and using the following assumptions: (i) the hind limb is representative of other muscular beds, (ii) the $\mathrm{A}-\mathrm{V}$ difference at one point of time is representative of the time average $A-V$ difference across that bed, and (iii) the splanchnic area receives $20 \%$ of the cardiac output, while the brain and the muscles receive $25 \%$ each. Applying the above, for example, one can calculate that there was production of $0.34 \mathrm{mmol}$ of lactate by the brain in the first $5 \mathrm{~min}$ after the administration of DCA, i.e., $0.46 \times 0.6 \times 0.25 \times 5=0.34$. Using similar calculations, and keeping in mind the limitations of the above assumptions, we estimated that the amount of ongoing production of lactate over a 30-min period after the administration of DCA was approximately $4 \mathrm{mmol}$. Removal of this amount of lactate via oxidation would require another $12 \mathrm{mmol}$ of $\mathrm{O}_{2}$.
} 
DCA, oxidation of lactate would seem to be a rather unlikely major mechanism for the effect of DCA to lower the level of lactate in blood.

The mechanism of the lactate-lowering effect of DCA in this model remains speculative. Lipogenesis is an unlikely mechanism, since it is a very slow metabolic process (Acheson et al. 1982; Hellerstein et al. 1991). It is possible that lactate was removed in this model via gluconeogenesis. The removal of $1 \mathrm{mmol}$ of lactate via gluconeogenesis requires the consumption of $0.5 \mathrm{mmol}$ of $\mathrm{O}_{2}$ (Halperin et al. 1992). From $\mathrm{A}-\mathrm{V}$ data across the splanchnic area, gluconeogenesis in the liver was not the site of removal of lactate (Table 3 ). This suggests that if gluconeogenesis was the pathway involved, it was stimulated in the kidney. Quantitatively, if the organ(s) that removed lactate (kidneys) consumed $25 \%$ of the total consumption of $\mathrm{O}_{2}$ over $30 \mathrm{~min}(1.3 \mathrm{mmol} / \mathrm{min} \times 30 \mathrm{~min} \times 0.25$. i.e, close to $10 \mathrm{mmol}$ of $\mathrm{O}_{2}$ ), it is possible that gluconeogenesis could be the pathway for the removal of lactate. In support of this view, the kidney is a major gluconeogenic organ in the rabbit (approximately $50 \%$ of oxygen consumption by the kidney of the rabbit is used for gluconeogenesis (K. S. Kamel, S. Cheema-Dhadli, and M. L. Halperin, unpublished observations). Nevertheless, an effect of DCA to stimulate gluconeogenesis in the kidney is not consistent with in vitro studies in which DCA was shown to inhbiit gluconeogenesis in rat kidney slices (Lacey and Randle 1978). Notwithstanding, the metabolic setting in vitro and in our model differ. If DCA stimulated gluconeogenesis in the kidney in vivo, perhaps it did so by stimulating PDH and thereby with a small flux of carbon provided a number of signals that can lead to stimulation of gluconeogenesis (e.g., Iacetyl-CoA, INADH, IATP/ ADP, IAMP) (Hers and Hue 1983). Although we attempted to test this hypothesis directly by canulating the renal vein percutaneously via the femoral or the jugular vein, we were unsuccessful. We could not use the abdominal approach of our previous studies because, in rabbits, this led to a very high level of fatty acids, which makes a major metabolic change in our model. Therefore the possibility that DCA has led to stimulation of gluconeogenesis in the kidney must remain a speculative one. However, it remains clear from the data that DCA led to the removal of lactate in this model via a mechanism other than simply promoting its oxidation.

To summarize, DCA was effective in lowering the level of lactate in blood in this model. The effect did not seem to be mediated via stimulation of oxidation of lactate. The results of our study emphasize the importance of defining the metabolic setting and performing a quantitative and biochemical analysis in evaluating the impact of a certain therapeutic modality in the treatment of a metabolic abnormality.

Abu Romeh, S., and Tannen, R. L. 1986. Therapeutic benefit of dichloroacetate in experimentally induced hypoxic lactic acidosis. J. Lab. Clin. Med. 107: 378-383.

Acheson, K. J., Flatt, J. P., and Jequier, E. 1982. Glycogen synthesis versus lipogenesis after a $500-\mathrm{g}$ carbohydrate meal. Metab. Clin. Exp. 1: $1234-1240$.

Blackshear, P. J., Fang, L. S. T., and Axeirod, L. 1982. Treatment of severe lactic acidosis with dichloroacetate. Diabetes Care, 5: $391-494$.

Cheetham, M., Boobis, L., Brooks, S., and Williams, C. 1986. Human muscle metabolism during sprint running. J. Appl. Physiol. 61 : $54-60$.

Cheng, K., and Larner, J. 1987. "Stable" effects of insulin and isoproterenol on adipocyte pyruvate dehydrogenase. Arch. Biochem. Biophys. 256: 699-702.

Denton, R. M., and Halestrap, A. P. 1979. Regulation of pyruvate metabolism in mammalian tissues. Essays Biochem. 15: 37-77.

Graf, H., Leach, W., and Arieff, A. I. 1985. Effects of dichloroacetate in the treatment of hypoxic lactic acidosis in dogs. J. Clin. Invest. 76: $919-923$.

Halestrap, A. W., and Poole, R. C. 1988. The transport of pyruvate and lactate across mitochondrial and plasma membranes. In Anion transport proteins of the red blood cell. Edited by M. Hamasaki and M. L. Jennings. Elsevier, Amsterdam. pp. 73-86.

Halperin, M. L., Vinay, P., Gougoux, A., Pichette, C., and Jungas, R. L. 1985. Regulation of the maximum rate of renal ammoniagenesis in the acidotic dog. Am. J. Physiol. 248: F607-F615.

Halperin, M. L., Kamel, K. S., and Cheema-Dhadli, S. 1992. "Figure" you made the correct diagnosis only when you have "counted" on it. Mt. Sinai J. Med. 59: 1-12.

Haynes, F. J., Cheema-Dhadli, S., Halperin, R. M., Zettle, R., Robinson, L., and Halperin, M. L. 1988. Effect of anaesthesia on insulin-induced hypoglycemia in rabbits. Can. J. Physiol. Pharmacol. 66: $1531-1537$.

Hellerstein, M. K., Christiansen, M., Kaempfer, S., Kletke, C., Wu, K., Reid, J. S., Mulligan, K., Hellerstein, N. S., and Shackleton, C. H. L. 1991. Measurement of de novo hepatic lipogenesis in humans using stable isotopes. J. Clin. Invest. 87: 1841-1852.

Hers, H. G., and Hue, L. 1983. Gluconeogenesis and related aspects of glycolysis. Annu. Rev. Biochem. 52: 617-653.

Holloway, P. A. H., and Alberti, K. G. M. M. 1975. Reversal of phenformin-induced hyperlactataemia by dichloroacetate in normal and diabetic rats. Diabetologia, 11: $350-351$.

Johnson, G. A. H., and Alberti, K. G. M. M. 1977. The metabolic effects of sodium dichloroacetate in experimental hepatitis in the rat. Biochem. Soc. Trans. 5: 1387-1389.

Jungas, R. L. 1971. Hormonal regulation of pyruvate dehydrogenase. Metab. Clin. Exp. 20: 45-53.

Kelman, G. R. 1966. Digital computer subroutine for the conversion of oxygen tension into saturation. J. Appl. Physiol. 21: 13751376.

Kelman, G. R. 1967. Digital computer procedure for the conversion of $\mathrm{PCO}_{2}$ into blood $\mathrm{CO}_{2}$ content. Respir. Physiol. 3: 111-115.

Lacey, J. H., and Randle, P. J. 1978. Inhibition of lactate gluconeogenesis in rat kidney by dichloroacetate. Biochem. J. 170: 551 560.

Loubatières, A. G., Valette, G., Ribes, G., Loubatières-Maiani, M. M., and Rondof, A. M. 1978. Dichloroacetate de sodium: son application à la thérapeutique des hyperlactatémies expérimentales. Diabete Metab. 4: 5-11.

Loubatières, A. L., Ribes, G., and Valette, G. 1976. Pharmacological agents and acute experimental hyperlactataemia in the dog. $\mathrm{Br}$. J. Pharmacol. 58: 429.

Merrill, G. F., Zambraski, E. J., and Grassl, S. M. 1980. Effect of dichloroacetate on plasma lactic acid in exercising dogs. J. Appl. Physiol. 48: 427-431.

Neely, J. R., and Morgan, H. E. 1974. Relationship between carbohydrate and lipid metabolites and the energy balance of heart muscle. Annu. Rev. Physiol. 36: 413-459.

Newsholme, E. A., and Start, C. 1977. Regulation of carbohydrate metabolism in muscle. In Regulation in metabolism. John Wiley \& Sons, London. pp. 106-130.

Park, R., and Arieff, A. I. 1982. Treatment of lactic acidosis with dichloroacetate in dogs. J. Clin. Invest. 70: $853-862$.

Roos, A. 1975. Intracellular $\mathrm{pH}$ and distribution of weak acids across cell membranes. A study of D- and L-lactate and of DMO in rat diaphragm. J. Physiol. (London), 249: $1-25$.

Stacpoole, P. W. 1989. The pharmacology of dichloroacetate. Metab. Clin. Exp. 38: 1124-1144.

Stacpoole, P. W., Harman, E. M., and Curry, S. H. 1983. Treatment of lactic acidosis with dichloroacetate. N. Engl. J. Med. 309: $390-396$. 
Stacpoole, P. W., Lorenz, A. C., Thomas, R. G., and Harman, E. M. 1988. Dichloroacetate in the treatment of lactic acidosis. Ann. Int. Med. 108(1): 58-63.

Taylor, S. I., Mukherjee, C., and Jungas, R. L. 1973. Studies on the mechanism of activation of adipose tissue pyruvate dehydrogenase by insulin. J. Biol. Chem. 248: 73-81.
Whitehouse, S., and Randle, P. J. 1973. Activation of pyruvate dehydrogenase in perfused rat heart by dichloroacetate. Biochem. J. 134: $651-653$.

Whitehouse, S., Cooper, R. H., and Randle, P. J. 1974. Mechanism of activation of pyruvate dehydrogenase by dichloroacetate and other halogenated carboxylic acids. Biochem. J. 141: 761-774. 